\title{
The role of the customary council in eliminating the phenomenon of revenge in the rural society: A field study on the customary council in a village in Sohag governorate, Egypt
}

\author{
Abd el-aal Hoda M." \\ Agricultural Extension and Rural Sociology Department, Faculty of Agriculture, Damietta University, Egypt
}

\begin{abstract}
This study aimed at identifying the role of the customary council to eliminate the phenomenon of revenge in rural community, Identify problems occurring during reconciliation between both sides of revenge. Finally, access to the most important proposals to confront the phenomenon of revenge. For the purposes of this study, the focus group method was used to determine the size of the 12 research subjects in the village of Al-Danakala, Al-Manshah district, Sohag governorate, Egypt. The study was used to analyze the data of this study in the questionnaire method by personal interview, and used to analyze the data of this study frequency, percentage, mean, reference, standard deviation and test $\mathrm{K}^{2}$. The main findings of the study were as follows:

1- $\quad$ Most of the respondents have a high degree of proficiency in dialogue and discussion as well as their ability to influence others. The weighted average of them is 30.8 degrees, 30.7 degrees.

2- The most important roles of the members of the Council are: taking pledges on the opponents after provoking the problem once again, and spreading tolerance among the members of society and eliminating the reasons that renew the problem again.

3- The two most important problems faced by Customary Council of Peace in resolving the problem of revenge between two families are: non-compliance with the decisions of the council, and replaced by the law, followed by bargaining millions for reconciliation (impossible conditions).
\end{abstract}

The study recommends to eliminate the phenomenon of revenge is:

1- Work to instill the values of religious and moral and customary right in the minds of young people.

2- The effective presence of the security services and the judiciary in order to resolve matters from the beginning.

3- Tighten the penalty for those who kill non-killer.

Keywords: the customary council, the phenomenon of revenge, the rural society, a field study, Sohag.

\footnotetext{
* Corresponding author: Abd el-aal Hoda M.
}

E-mail address: hodamostafa159@gmail.com 


\title{
دور المجلس العرفي في القضاء على ظاهرة الثأر بالمجتمع الريفي: در اسة ميدانية على أعضاء المجلس العرفي بأحدي قري محافظة سوهاج برهمهورية مصر العربية
}

\author{
هدى مصطفى عبدالعال محمد
}

قسم الإرشاد الزراعي و المجتمع الريف، يكلية الزراعة، جامعة دمياط، جمهورية مصر العربية

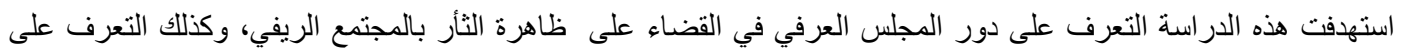

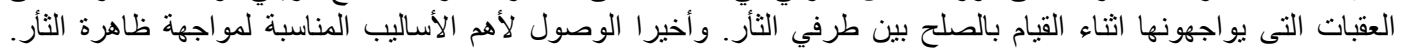

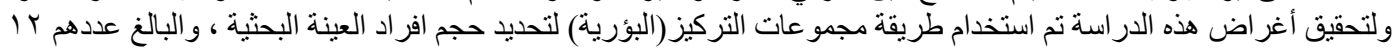

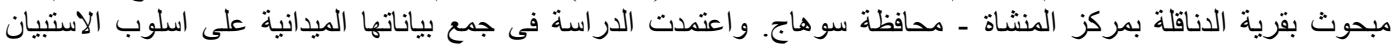

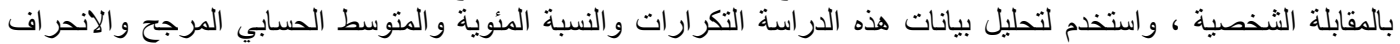

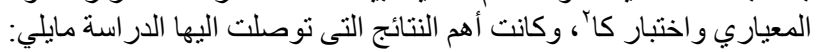

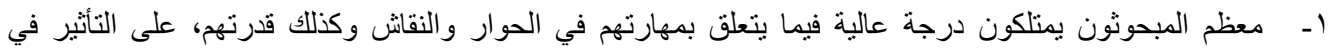

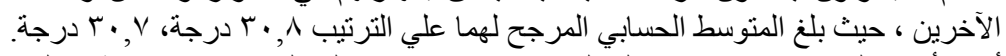

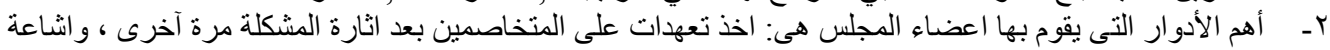

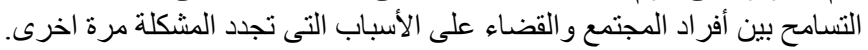

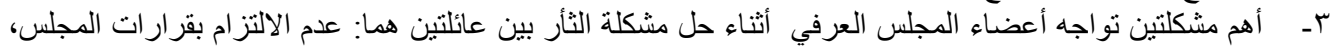

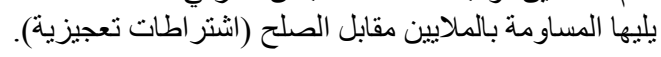

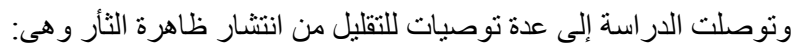

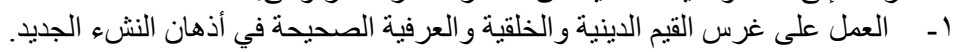

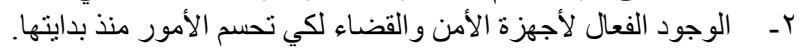

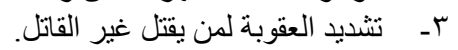

كلمات دالة: المجلس العرفي، ظاهرة الثأر، المجتمع الريفي، دراسة ميدانية، سوهاج. 
وسائل الاتصال والاعلام ودخول العديد من الأدوات الحديثة

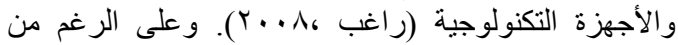

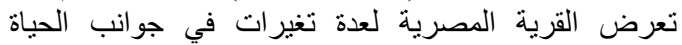

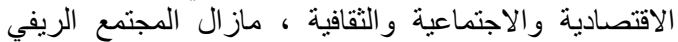

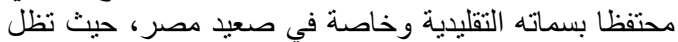

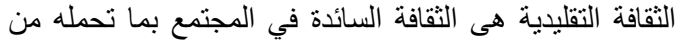

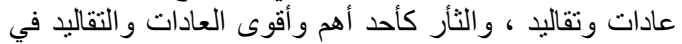

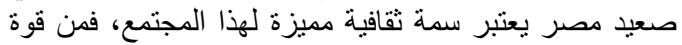

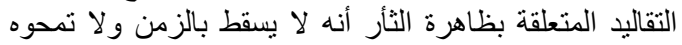

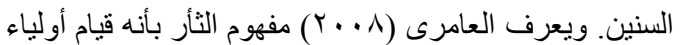

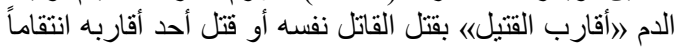

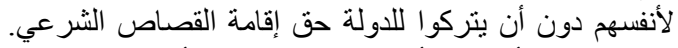

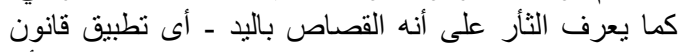

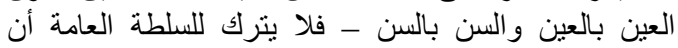

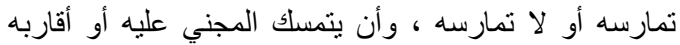

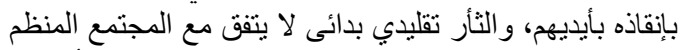

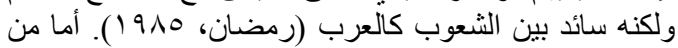

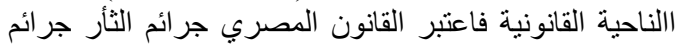

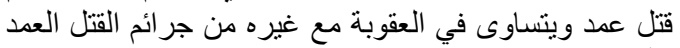

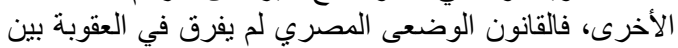

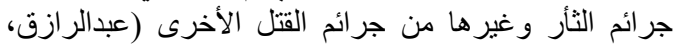

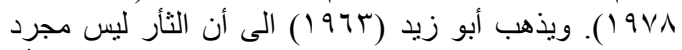

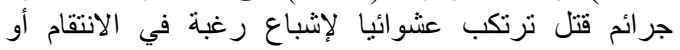

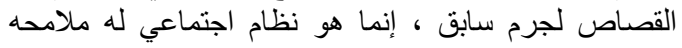

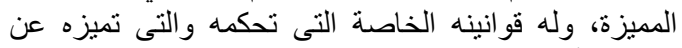
جر ائم الثأر العادية و هذه القو انين هي:

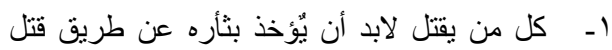

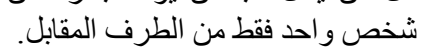

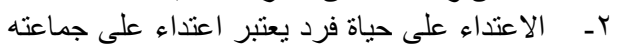

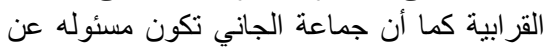
جريمته.

r- ل لا يؤخذ الثأر إلا من الرجل البالغ القادر على حمل السلاح و قادر على الافخاع عن نفسه.

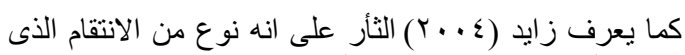

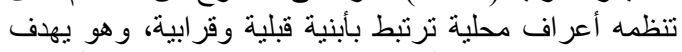

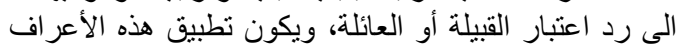

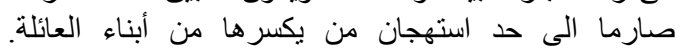

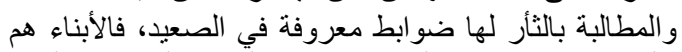

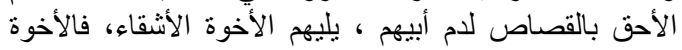

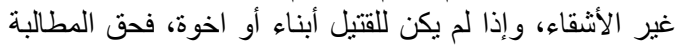

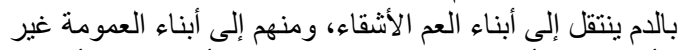

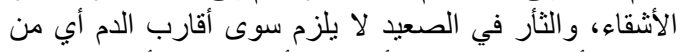

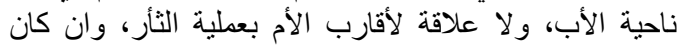

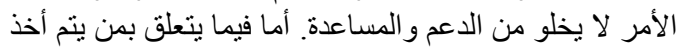

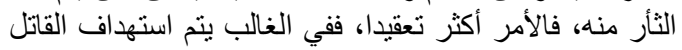

تعد ظاهرة الأخذ بالثأر من أسوء العادات الاجتماعية الموروثة

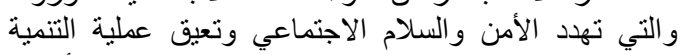

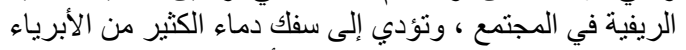

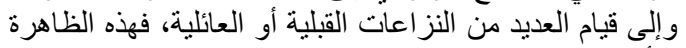

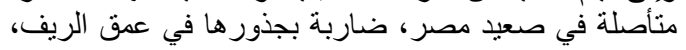

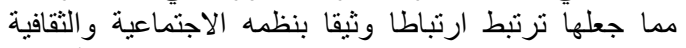

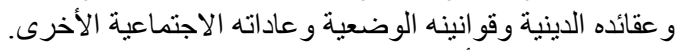

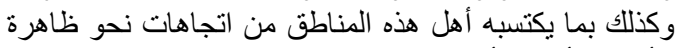

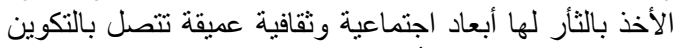

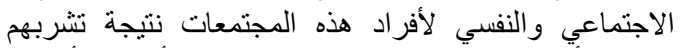

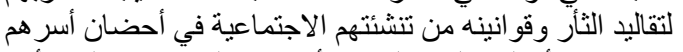

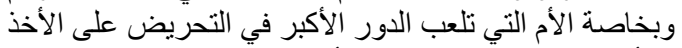

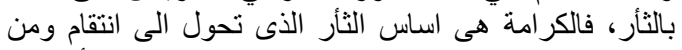

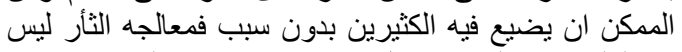
فى العلم او فى الدين فقط بل فى نغيير ثقافة هذا المجمع.

\section{المشكلة البحثية}

رغم أن الثأر ظاهرة عالمية إلا أن طقوسه المتوارثة في

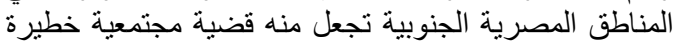

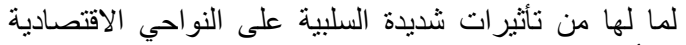

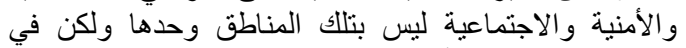

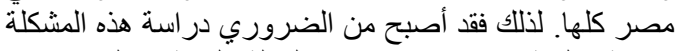

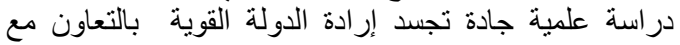

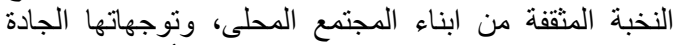

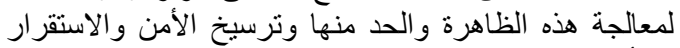

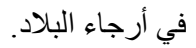

\section{الأهداف البحثية}

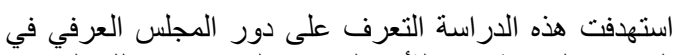

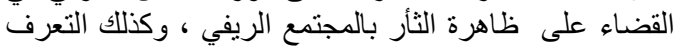

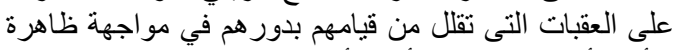
الثأر. و أخيرا الوصول لأل لهم الأساليب المناسبة لمو اجهة ظاهرة

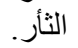

\section{الإطار النظري والمرجعي}

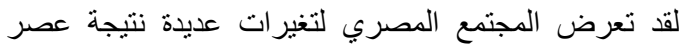

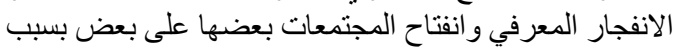

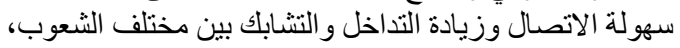
وقد انعكست هذه التغيرات على القدية التهية المصرية في الآونة

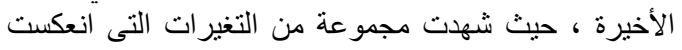
على جو انب كثيرة في الحياة الاقتصادية و والاجنماعية و الثقافية الثية،

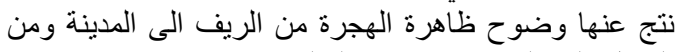

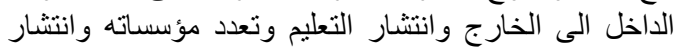


البحث، كما تم إجراء اختبار مبدئى للاستمارة على عينة

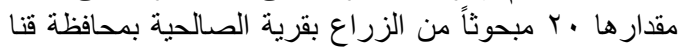

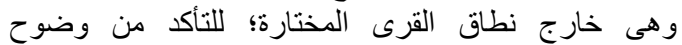

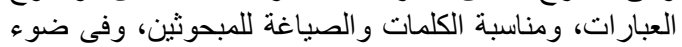

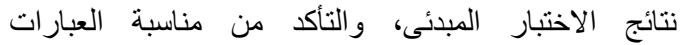

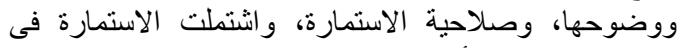

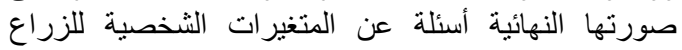

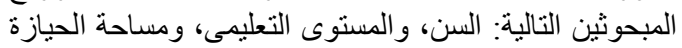

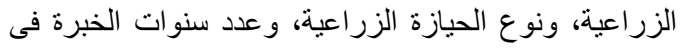

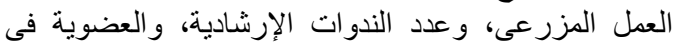

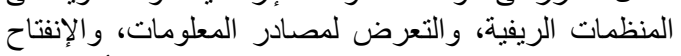

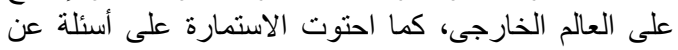

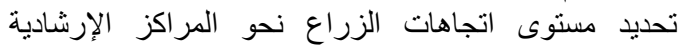

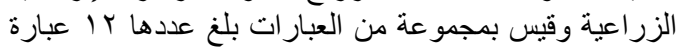

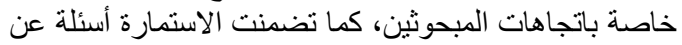

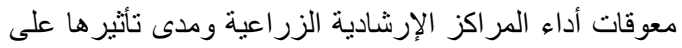

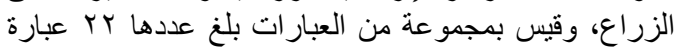

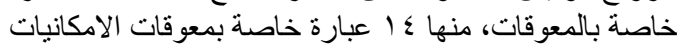

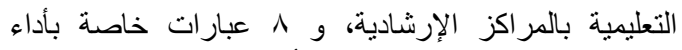

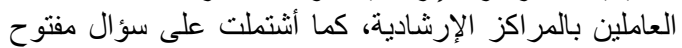

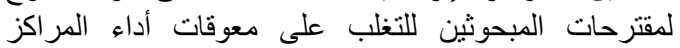

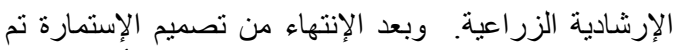

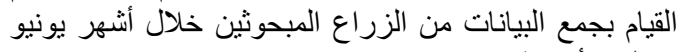

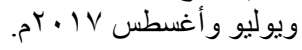

\section{مميزات المجلس العرفي مقارنة بالقضاء الرسمي}

يوضح محجوب (0 . . ب) أوجه الاختلاف أو التعارض بين

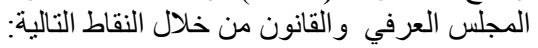

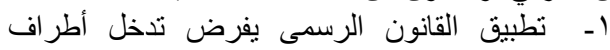

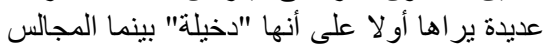

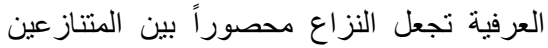
الذين قد يكونوا من نفس العائلة.

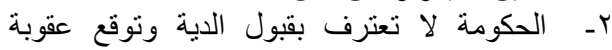

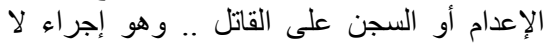
يصل بالخصو مة إلى تسوية مرضية. الإنية.

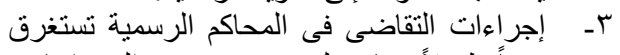

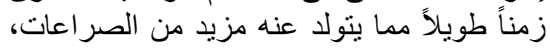

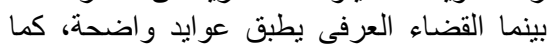

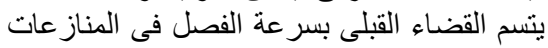
وتحديد حقوق كل من الخصوم.

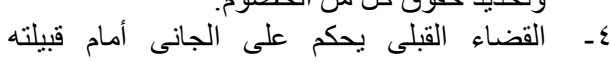

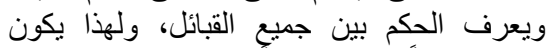
الحكم موجعاً للجانى ر رادعاً لغيره.

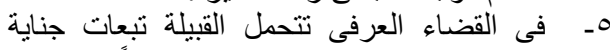
الجانى. ولهذا نجد القبيلة تمارس ضبطاً لسلوكيات

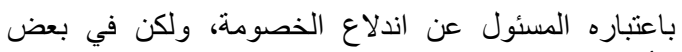

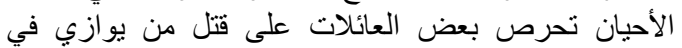

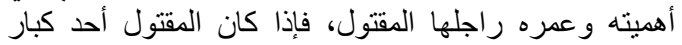

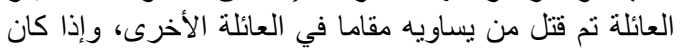

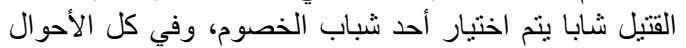

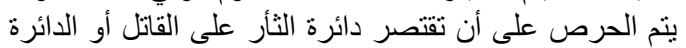

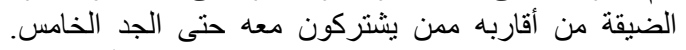

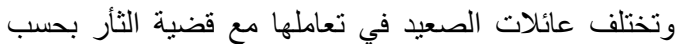

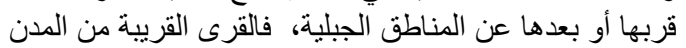

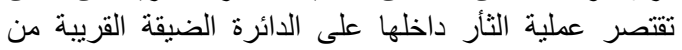

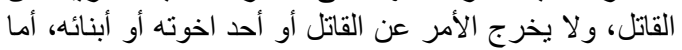

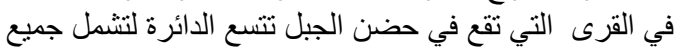
أفراد العائلة، الذين يشتركون جميعا في أخذ الثأر أو تحمل الذئ

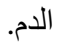

\section{المجلس العرفي (بدائل الثأر)}

بعد مرور مدة من الزمن على وقوع الجريمة يسعى أهل القاتل

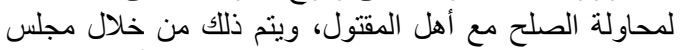

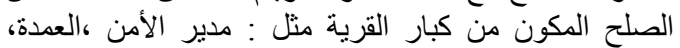

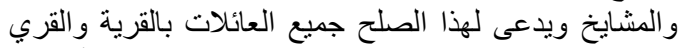

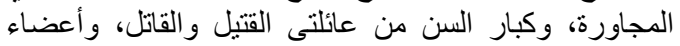

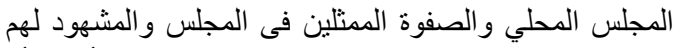

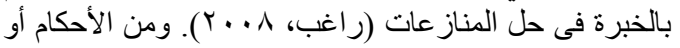
القرارات التى يصدر ها مجلس الصلح ما يلي:

1- القودة (الجر اءة): هي تللك العملية التى تتم عقب

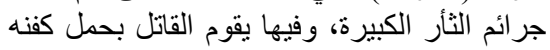
بين يديه ويذهب الى أسرة القتيل طالبا منهم الصلح

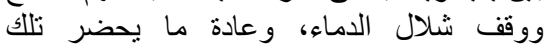

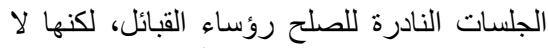

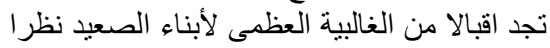

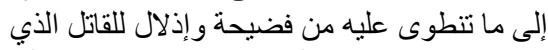

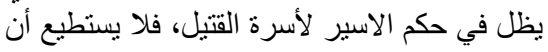

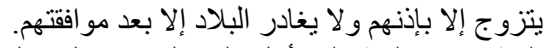

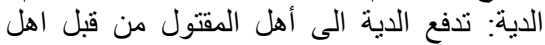

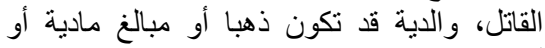

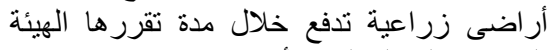

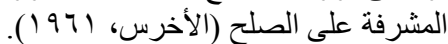

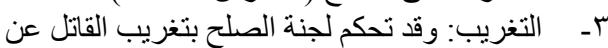

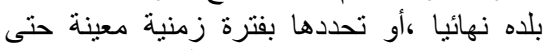

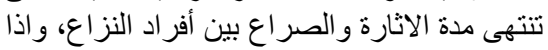

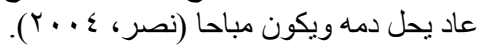

\section{جمع البيانات}

تم جمع بيانات هذا البحث عن طريق المقابلة الشخصية باستخدام استمارة استبيان سبق إعدادها فى ضو ضو أبـ أهداف 


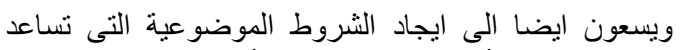

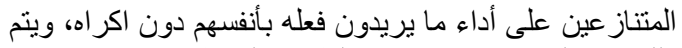

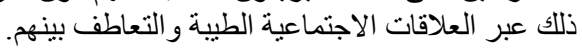

$$
\text { الفرض البحثي }
$$

لا توجد فروق ذات دلالة احصائية بين افر اد العينة البحثية فيما

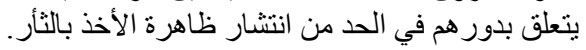

\section{منهجية الدراسة}

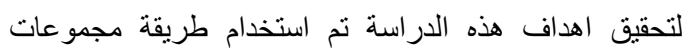

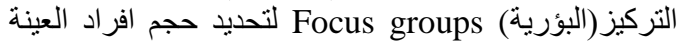
البحثية ، والبالغ عددهم 1 البورية مبحوث بقرية الدناقلة بمركز

المنشاة ـمحافظة سو هاج بجمهورية مصر العربية.

\section{مجتمع البحث (اعضاء المجلس العرفي)}

ا - شيخ العمد: هو العمدة على كل عمد المر اكز وقر اه

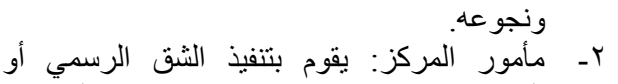

القانوني كجهة ادارية ، ويستخدم عنصر التهر الترغيب التريب

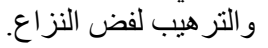

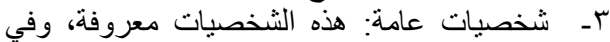

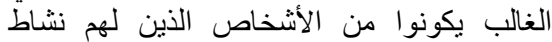

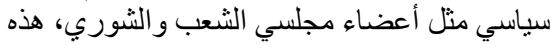

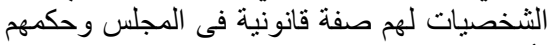

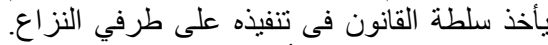

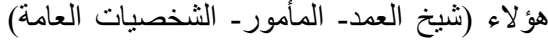
يكونوا على مستوي المركز وفي حالة تنفيذ الصلح الصنح

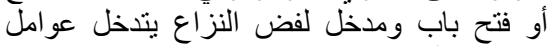

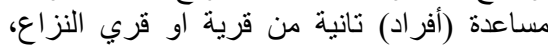

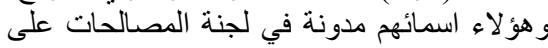

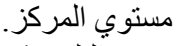

ع - عمدة البلد وشيخ البلد التى بها النزاع: فلا يمكن للأشخاص السابقة الذكر التعدي على عمدة البلى القرية

$$
\text { وشيخها. }
$$

0ـ القيادات البارزة في القرية: مثل دكاترة الجامعة ،

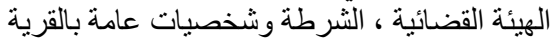

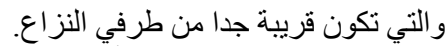

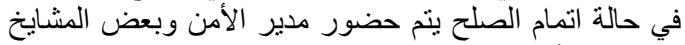
وقر اء القرآن.

\section{النتائج ومناقشتها}

\section{أولاً: وصف المتغيرات البحثية}

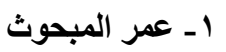

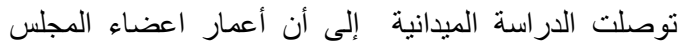

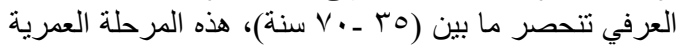

أفرادها حتى لا يوقعونها فى مأزق دفع قيمة الديات الباهظة.

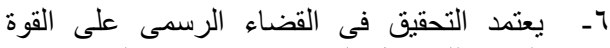

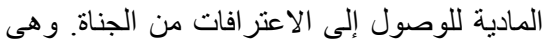

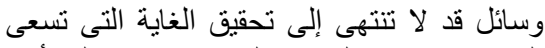

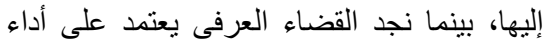

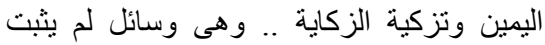

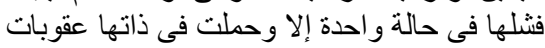

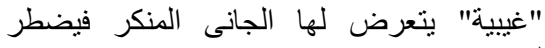
للاعتر اف بجريمته. -V

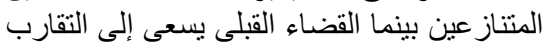

$$
\text { بينهما. }
$$

ويتسم أعضاء المجلس العرفي بقلة العدد نسبياً باعتبارهم

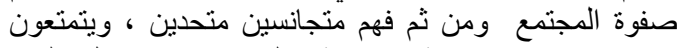

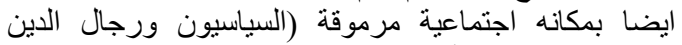

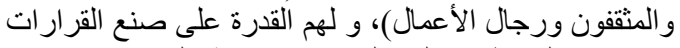

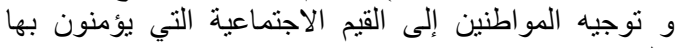

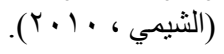

\section{التوجهات النظرية المفسرة لاور النخبة المثقفة فى الحد من ظاهرة الأخذ بالثأر النغرة}

من النظريات التى تفسر دور النخبة المثقفة النظرية التفاعلية

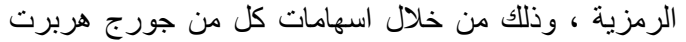

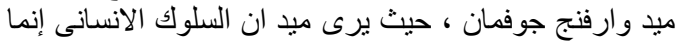

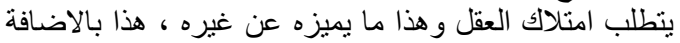

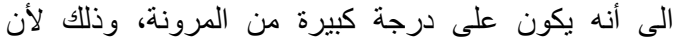

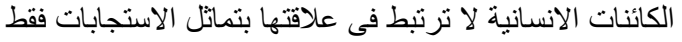

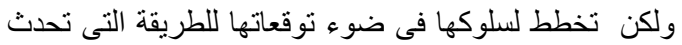

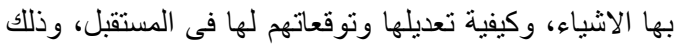

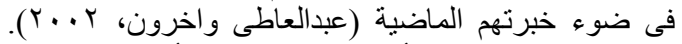

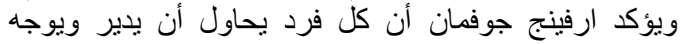

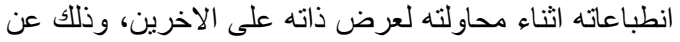

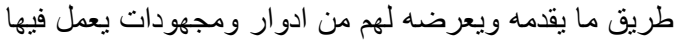

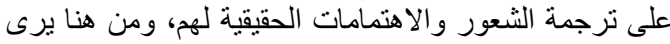

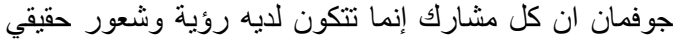

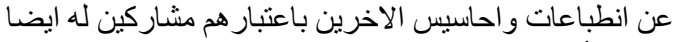

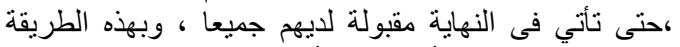

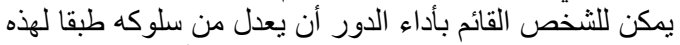

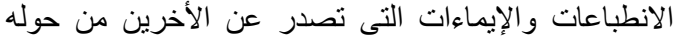

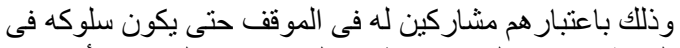

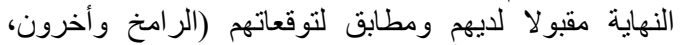

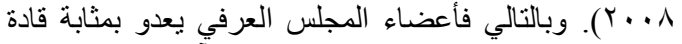

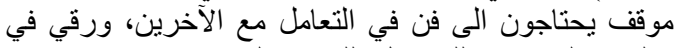

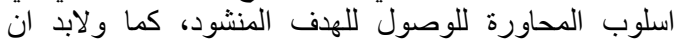
يمتلكون القيم والحقائق التى تحدد مفاهيم الصورة الصورة الثاملة عن المشكلة المطروحة وبالتالي يستطيعون نقلها للآخرين. 
مهندسين زر اعيين، محامي، مدير سابق. ع - مهارات الحوار والنقاش

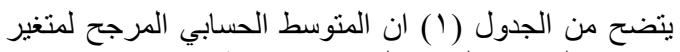

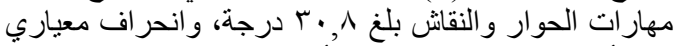
, r,

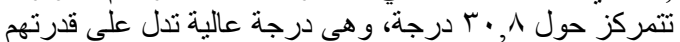

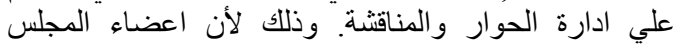

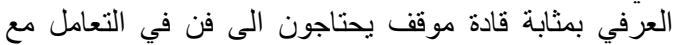

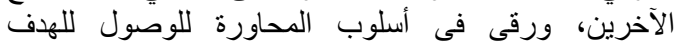

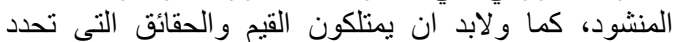

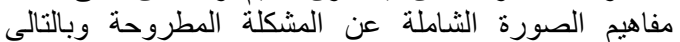

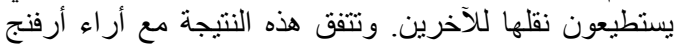

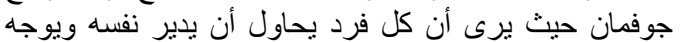

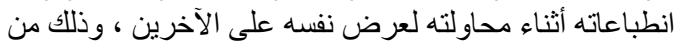

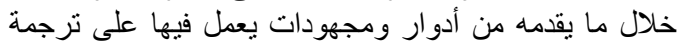
الثعور والاهتمام الحقيقي بالآخرين.

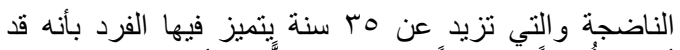

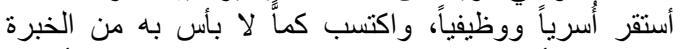

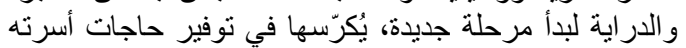

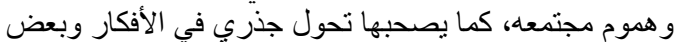

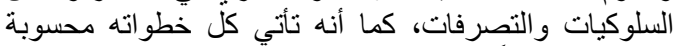

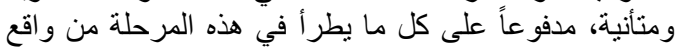
شعوره بالمسؤولية الاجتماعية.

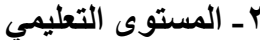

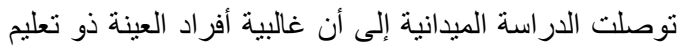
عالي بنسبة 7,77\% من اجمالي حجم العينة البحثية.

\section{بـ المهنة}

توصلت الدر اسة الميدانية إلى تتوع واختلاف مهن أفر اد العينة

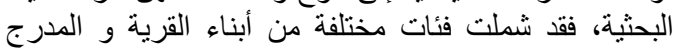

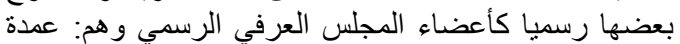
البلد، شيخ البلد، مستشار، مدرس، دكتورين جاءمئ الرعيين، طبييين،

جدول ( ) : توزيع أفر اد العينة البحثية وفقا لمتغير مهارات الحوار و النقاش.

\begin{tabular}{|c|c|c|c|c|}
\hline \multirow{3}{*}{ 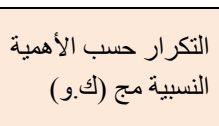 } & \multicolumn{3}{|c|}{ التكرار } & \multirow{3}{*}{ مهارات الحوار و النقاش } \\
\hline & بدرجـــــــة & بدرجــــــة & بدرجـــة & \\
\hline & ضعيفة & متوسطة & عالية & \\
\hline$\mu_{1}$ & - & 0 & $\mathrm{r}$ & الإنصات للآخرين لفترة طويلة اثناء مجلس الصلح؟ \\
\hline Tr & - & r & 9 & الاقتداء بأصحاب مجالس الصلح القدماء؟ \\
\hline r & - & r & 9 & الاستشهاد بقصص سابقة عن مشكلة الثأر اثثاء الصلح بين المتخاصمين؟ \\
\hline$r \varepsilon$ & r & . & $\varepsilon$ & الاستشهاد بأمثال دارجة اثناء الصلح بين المتخاصمين؟ \\
\hline Tr & 1 & 1 & 1 . & الاستشهاد بآيات قر أنية وأحاديث شريفة أثناء الصلح بين المتخاصمين؟ \\
\hline
\end{tabular}

\section{ثانياً: دور الأعضاء فى المجلس العرفي}

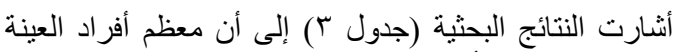

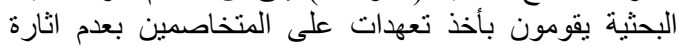

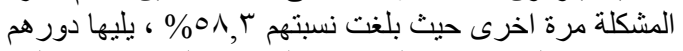

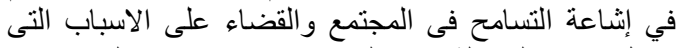

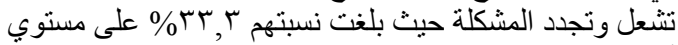

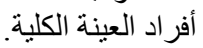

0ـ القدرة على التأثير فى الآخرين

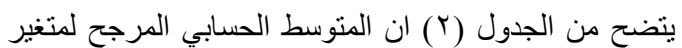

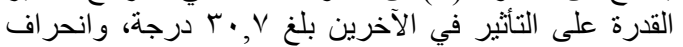

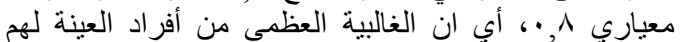

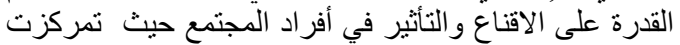

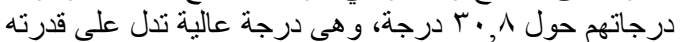
علي قيادة الموقف و وادارته.

جدول (r): توزيع أفراد العينة البحثية وفقا لمتغير القدرة على تأثير في الآخرين.

\begin{tabular}{|c|c|c|c|c|}
\hline \multirow{3}{*}{ الأهمية النسبية } & \multicolumn{2}{|c|}{ 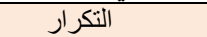 } & \multirow{3}{*}{ عالية } & \multirow{3}{*}{ القدرة على التأثير فى الأخرين } \\
\hline & بدرجة & بدرجة & & \\
\hline & ضعيفة & متوسطة & & \\
\hline M & - & 0 & V & الاستماع لحديث الاخرين بغض النظر عما يقوله هل يو افقك أو يخالفك ؟ \\
\hline एะ & - & r & 1 . & تقريب وجهات النظر بين المتخاصمين للوصول الى حل يرضى الطرفين؟ \\
\hline rV & - & 7 & ○ & تلخيص حديث المتخاصمين بدون مقاطعتهم قبل الخوض في الحديث . \\
\hline
\end{tabular}




\begin{tabular}{|c|c|c|}
\hline$\%$ & تكرار & الدور \\
\hline ז.r & $\varepsilon$ & اشـاعة التسامح فى المجتمع و القضاء على الاسباب التى تشعل وتجدد المشكلة \\
\hline $0 \Lambda . r$ & $\checkmark$ & اخذ تعهدات على المتخاصمين بعدم اثارة المشكلة مرة اخرى \\
\hline A.r & 1 & تصفية النفوس بإرضاء كل طرف سو اء بالحكم على الجاني أو بتحقيق رغبات المجني علبه \\
\hline
\end{tabular}

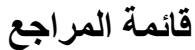

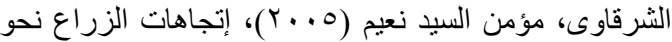

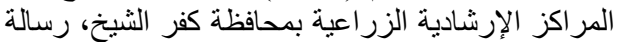

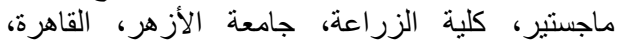

$$
\text { جمهورية مصر العربية. }
$$

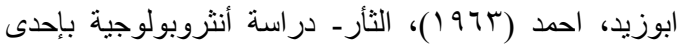

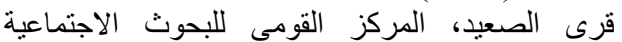
و الجنائية، القاهرة، جمهورية مصر العرى العربية.

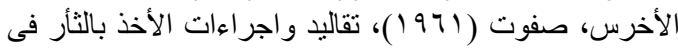

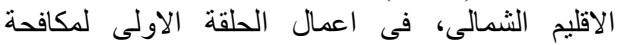

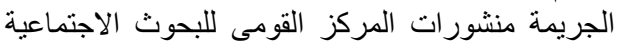

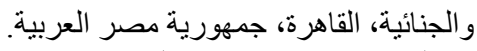

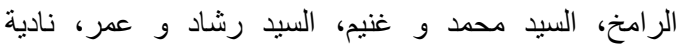

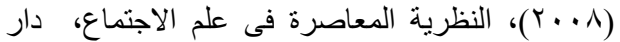

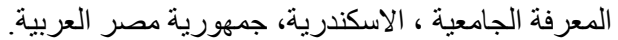

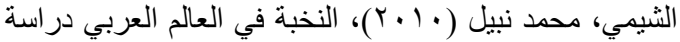

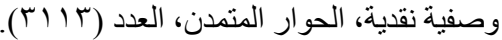

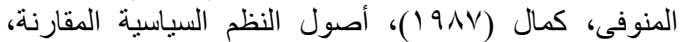

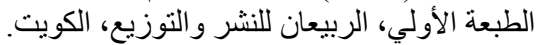

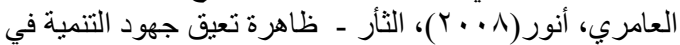

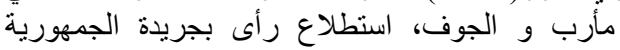

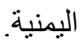

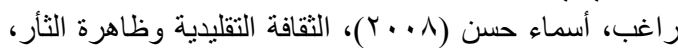
رسالة ماجستير، كلية الآداب، جامعة سو هاج، جمهورية البهاء

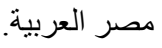

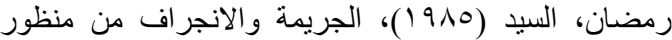

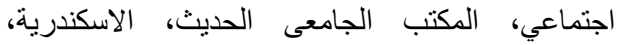

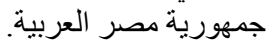

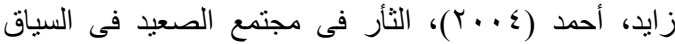

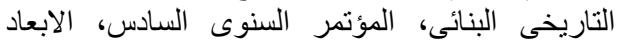

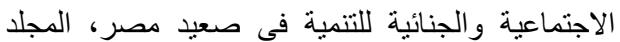

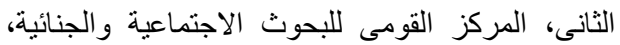

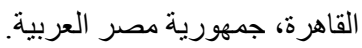

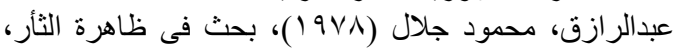

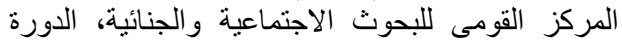

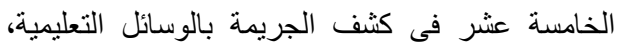
القاهرة، جمهورية مصر العربية. عبد العاطى، السيد و بيومى، محمد احمد و جابرة، سامية محمد

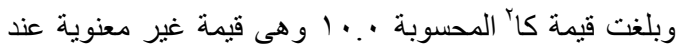

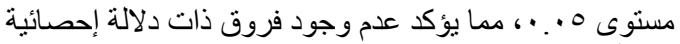

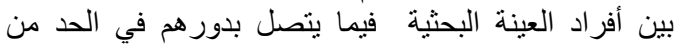

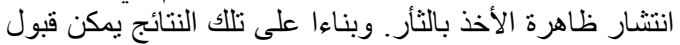

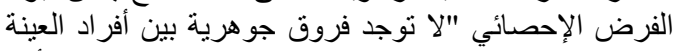

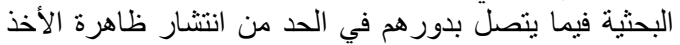

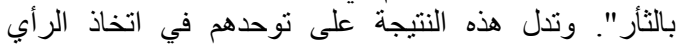

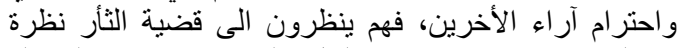

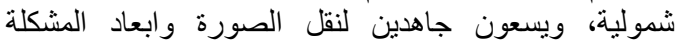

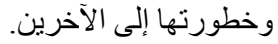

ثالثاً: اهم العقبات التى تواجه الأعضاء اثناء القيام بالصلح بين عائلتين بينهم ثأر الثيات

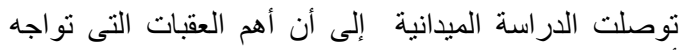

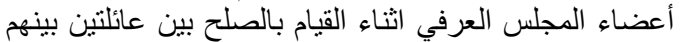

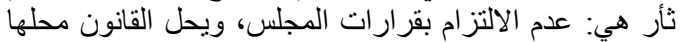

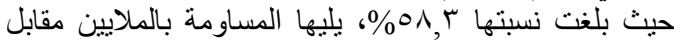

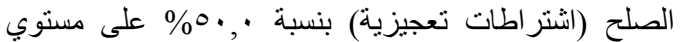

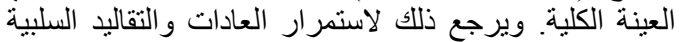

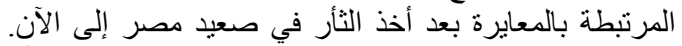

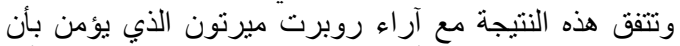

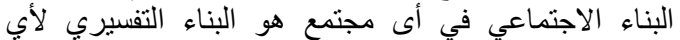

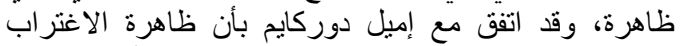

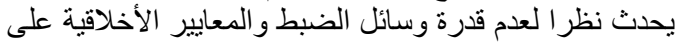
وضع حدود لطموحات الناس ونطلعاتهر.

\section{رابعاً: أهم الأساليب المناسبة لمواجهة ظاهرة الأخذ} بالثأر

وصلت الدراسة الميدانية إلى أن معظم أفراد العينة البحثية

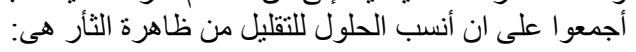
ا. العمل على غرس القيم الدينية والخلقية والعرفية الصحيحة في أذهان النشء الجديد.

r. . وضع خطة عملية للمشايخ و النخبة المثقفة بالبلد.

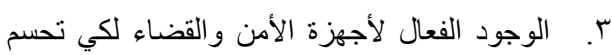

$$
\text { الأمور منذ بدايتها. }
$$

ع. ـثنديد العقوبة لمن يقتل غير القاتل. 


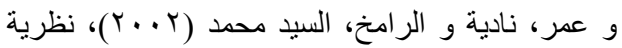

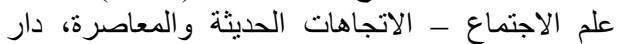

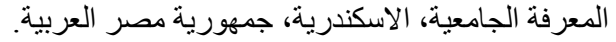

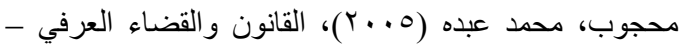

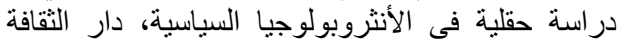
العلمية، الاسكندرية، جمهورية مصر العربية العبية.

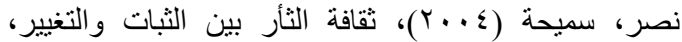

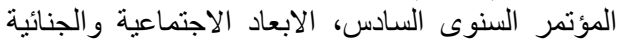

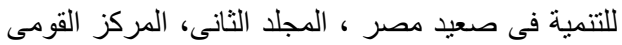
للبحوث الاجتماعية والجنائية ، القاهرة. 